\title{
Vasculogenic mimicry is associated with high tumor grade, invasion and metastasis, and short survival in patients with hepatocellular carcinoma
}

\author{
BAOCUN SUN ${ }^{1,2}$, SHIWU ZHANG ${ }^{1}$, DANFANG ZHANG ${ }^{1}$, JING DU $^{1}$, \\ HUA GUO $^{1}$, XIULAN ZHAO $^{2}$, WEI ZHANG ${ }^{3}$ and XISHAN HAO ${ }^{1}$ \\ ${ }^{1}$ Department of Pathology, Tianjin Cancer Hospital, Tianjin Medical University, Tianjin 300060; \\ ${ }^{2}$ Department of Pathology, Tianjin Medical University, Tianjin, P.R. China; ${ }^{3}$ Department of Pathology, \\ The University of Texas M. D. Anderson Cancer Center, Houston, TX 77030, USA
}

Received April 20, 2006; Accepted May 29, 2006

\begin{abstract}
Vasculogenic mimicry (VM) has increasingly been recognized as a form of angiogenesis. In VM, epithelial cells are integrated into the malignant tumor vasculature. An association has been observed between VM and poor clinical prognosis in some malignant tumors. However, whether $\mathrm{VM}$ is present and clinically significant in hepatocellular carcinoma (HCC) is unknown. In this study, we determined whether VM was present in HCC and whether it was associated with tumor grade, invasion and metastasis, and survival duration. We collected paraffin-embedded HCC tumor samples, along with complete clinical and pathologic data for all the cases, and performed immunohistochemical staining for CD31, CD105 (endoglin), hepatocyte, vascular endothelial growth factor, matrix metalloproteinase (MMP)-2, and MMP-9. The VM status was compared with the clinical and pathological data using statistical tests. Kaplan-Meier survival analysis and log-rank test were used to compare survival durations between patients with and without VM. The VM vessel cells were CD31 and CD105-negative and hepatocyte and vascular endothelial growth factor-positive, showing that they were not derived from endothelial cells but were HCC tumor cells. Patients with VM had a higher metastasis rate than did those without VM $(\mathrm{P}=0.003)$. Consistent with this finding, MMP-2 and MMP-9 were present in all the VM cases but were found less frequently in non-VM cases $(\mathrm{P}<0.05)$. The Kaplan-Meier survival analysis showed that patients in the VM group had a significantly shorter survival duration than did those in the non-VM
\end{abstract}

Correspondence to: Dr Xishan Hao, Tianjin Cancer Hospital, Tianjin Medical University, Tianjin 300060, P.R. China

E-mail: zhangshiwu666@yahoo.com.cn

Dr Wei Zhang, Department of Pathology, Unit 85, The University of Texas M.D. Anderson Cancer Center, 1515 Holcombe Blvd., Houston, TX 77030, USA

E-mail: wzhang@mdanderson.org

Key words: vasculogenic mimicry, hepatocellular carcinoma, angiogenesis group. In conclusion, VM is a marker of poor clinical prognosis in HCC: Its presence may be associated with a high tumor grade, invasion and metastasis, and short survival.

\section{Introduction}

Malignant tumors require an adequate blood supply to support their growth. Vasculogenesis/angiogenesis is the most recognized cellular process that is activated in tumors to fulfill this need, and new vessel formation and microvascular proliferation are hallmarks of advanced cancer.

Extensive studies have revealed that tumor cells produce growth factors such as the vascular endothelial growth factor (VEGF) and the basic fibroblast growth factor (FGF) to stimulate endothelial cell proliferation. Endothelial cells have an intrinsic ability to assemble into blood vessels, and it was believed that only endothelial cells could form blood vessels. However, blood vessels' rigid cellular identity has been challenged by the observation that tumor cells formed blood vessels in melanoma $(1,2)$. The process by which a vessel is formed from tumor cells is termed vasculogenic mimicry (VM).

Endothelial cells are not demonstrable in VM vessels on CD31 immunostaining, but cells lining the VM vessels are, as expected of cells of hepatic origin, periodic acid-Schiff (PAS)-positive. The presence of red blood cells indicates that blood circulates in the VM vessels. Indocyanine-green was injected into the uveal veins of mice, and various PAS-positive patterns were seen in the melanoma tissue using laser confocal microscopy, establishing that VM vessels are also capable of microcirculation.

VM vessels are not a consequence of hemorrhage and necrosis of tumors because no necrosis or inflammatory cells are found around them. Apparently, when the growth of endothelium-dependent vessels is not sufficient for the rapid proliferation of tumor tissues, some tumor cells alter their gene expression program and cell fate to those of endothelial cells. Further, the tumor cells lining the VM vessels secrete matrix metalloproteinases (MMP)s and express vascular endothelial (VE)-cadherin and laminin to induce extracellular matrix remodeling to promote the formation of $\operatorname{VM}(3,4)$. 
Accumulating evidence has demonstrated that many different tumor types use VM to form a blood supply network to support tumor cell growth, invasion, and metastasis (5). VM has been reported in inflammatory breast cancer (6), prostate cancer (7), invasive ovarian cancer (8), sarcoma (9), and astrocytoma (10). VM is also involved in the invasion and metastasis of malignant tumors $(6,7,11)$ and has been associated with poor prognosis in melanoma and sarcomas $(8,9)$.

Whether VM is present and clinically significant in hepatocellular carcinoma (HCC) is unknown. The question is important because HCC affects a large population worldwide and is one of the leading causes of cancer death in many countries, especially in China (12). HCC is highly vascular and has a poor prognosis (13). In 2003, Dupuy et al (14) reported that the secretion of extracellular matrix remodelingassociated proteins led to the growth of hepatocytes with endothelial phenotypes in the vessel walls of HCC tumors in transgenic mice. Therefore, we determined whether VM is present and clinically significant in patients with HCC.

In this study, we performed an immunohistochemical analysis of archived HCC tissue samples to identify VM and to determine the invasion status of the tumors. We then compared the VM status with the clinical data to determine whether VM was associated with tumor grade, metastasis, and survival duration. We found that VM was present in HCC and that its presence was associated with high tumor grade, invasion and metastasis, and short survival.

\section{Materials and methods}

Tissue samples. Paraffin-embedded HCC tumor tissue samples were obtained from the Tumor Tissue Bank of Tianjin Cancer Hospital from 1980-1990. The diagnosis of these HCC samples was verified by pathologists. Detailed pathologic and clinical data were collected for all the samples, including Edmondson tumor grade, metastasis, and survival duration. We collected paraffin-embedded tumor tissue samples from patients who had not undergone therapy prior to tumor surgical operation. Ninety-nine patients were included, 76 males (mean age, 52.43 \pm 9.94 years) and 23 females (mean age, 50.39 \pm 14.12 years). The survival durations ranged from 1 to 72 months (mean, 24.91 16.64 months). Of the 99 patients, two had Edmondson grade I tumors, 38 had Edmondson II, 36 had Edmondson III, and 23 had Edmondson IV. The use of these tissues in this study was approved by the institutional research committee.

$H \& E$ and PAS staining. Four-micrometer sections from formalin-fixed, paraffin-embedded tissue were mounted on poly-L-lysine-coated slides. The slides were air-dried and the tissue deparaffinized and rehydrated. As for PAS staining the sections were then rinsed with distilled water for $5 \mathrm{~min}$ and incubated with periodic acid-Schiff (PAS) for $15 \mathrm{~min}$. Finally, all of the sections were counterstained with hematoxylin for $10 \mathrm{~min}$ and eosin for $2 \mathrm{~min}$.

Immunohistochemical and histochemical double-staining. To confirm the identity of the cells lining the walls and whether VM was present in the tissues, we used the primary antibodies mouse monoclonal anti-CD31, hepatocyte, VEGF
(Santa Cruz, CA), CD105 (endoglin; Zymed, San Francisco, CA), MMP-9, and MMP-2 (LabVision-Neomarkers Chemical Co., New York, NY), all at a dilution of 1:100. The staining systems except for PAS staining used in this study were PicTure PV6000 (Zhongshan Chemical Co., Beijing, China) and Elivision Plus (Zhongshan Chemical Co. Beijing).

Formalin-fixed, paraffin-embedded tissue was cut at $4 \mu \mathrm{m}$, dried for $4 \mathrm{~h}$ at room temperature and deparaffinized in xylene. Subsequently, the sections were rehydrated through graded alcohols into water. Heat-induced epitope retrieval was achieved in $0.01 \mathrm{M}$ citric acid buffer $(\mathrm{pH}$ 6.0) in a microwave oven and EDTA buffer ( $\mathrm{pH} 8.9)$ for CD105. After being boiled for $10 \mathrm{~min}$, the sections were left to cool at ambient temperature for $20 \mathrm{~min}$ and then rinsed thoroughly with water and placed in PBS for $5 \mathrm{~min}$. Endogenous peroxidase was blocked with $3 \%$ hydrogen peroxide in $50 \%$ methanol at ambient temperature for $10 \mathrm{~min}$, and the slides were rinsed with PBS. The sections were then incubated with CD31, hepatocyte, and CD105 for PV6000 and VEGF, MMP-2, and MMP-9 for Elivision Plus overnight at $4{ }^{\circ} \mathrm{C}$. The secondary antibody was added, and the sections were incubated for $20 \mathrm{~min}$ at $37^{\circ} \mathrm{C}$. Visualization was performed using the diaminobenzidine method (Zhongshan Chemical Co.) according to the manufacturer's instructions. Appropriate positive and negative controls for each antibody were used.

CD31, hepatocyte, CD105, VEGF, MMP-2, and MMP-9 levels were quantified according to the method described by Mattern et al (15), and both the intensity and percentage of positive cells were measured. More than 10 microscopic fields in one section were observed under $\mathrm{x} 400$ magnification. Positive cells were counted in 100 tumor cells per field, 10 fields in each section. The number of positive cells was visually evaluated and cell expression was stratified as follows: 0 (negative) for $<10 \%$ positive cells, 1 (weak) for $<25 \%$ positive cells, 2 (moderate) for $<50 \%$ positive cells, and 3 (strong) for $>50 \%$ positive cells. The sum (staining index) of stain intensity and positive cell scores was used to determine the final result for each section.

Statistical analysis. The statistical analysis was performed using SPSS statistical analysis software (SPSS, Chicago, IL). A P-value of $<0.05$ was considered significant. The following statistical analysis methods were used: The $\chi^{2}$ test for the positive rate comparison between two groups, the Student's ttest for normal distributive data, and the Mann-Whitney test for non-normal distributive data. A Kaplan-Meier survival analysis and log-rank test were performed to compare survival times between patients in the VM and non-VM groups.

\section{Results}

$V M$ present in HCC. VM was identified by the presence of red blood cells in vessels lined by tumor cells, not by endothelial cells, and by the absence of necrosis and inflammatory cells infiltrating around the channels. VM was found in 12 HCC samples (12\%) (Fig. $1 \mathrm{~A}-\mathrm{C})$. The cells were negative for CD31 and CD105, indicating that they were not endothelial or endothelial progenitor cells (Fig. 1B and D). Rather, the cells stained positive for hepatocyte, indicating 


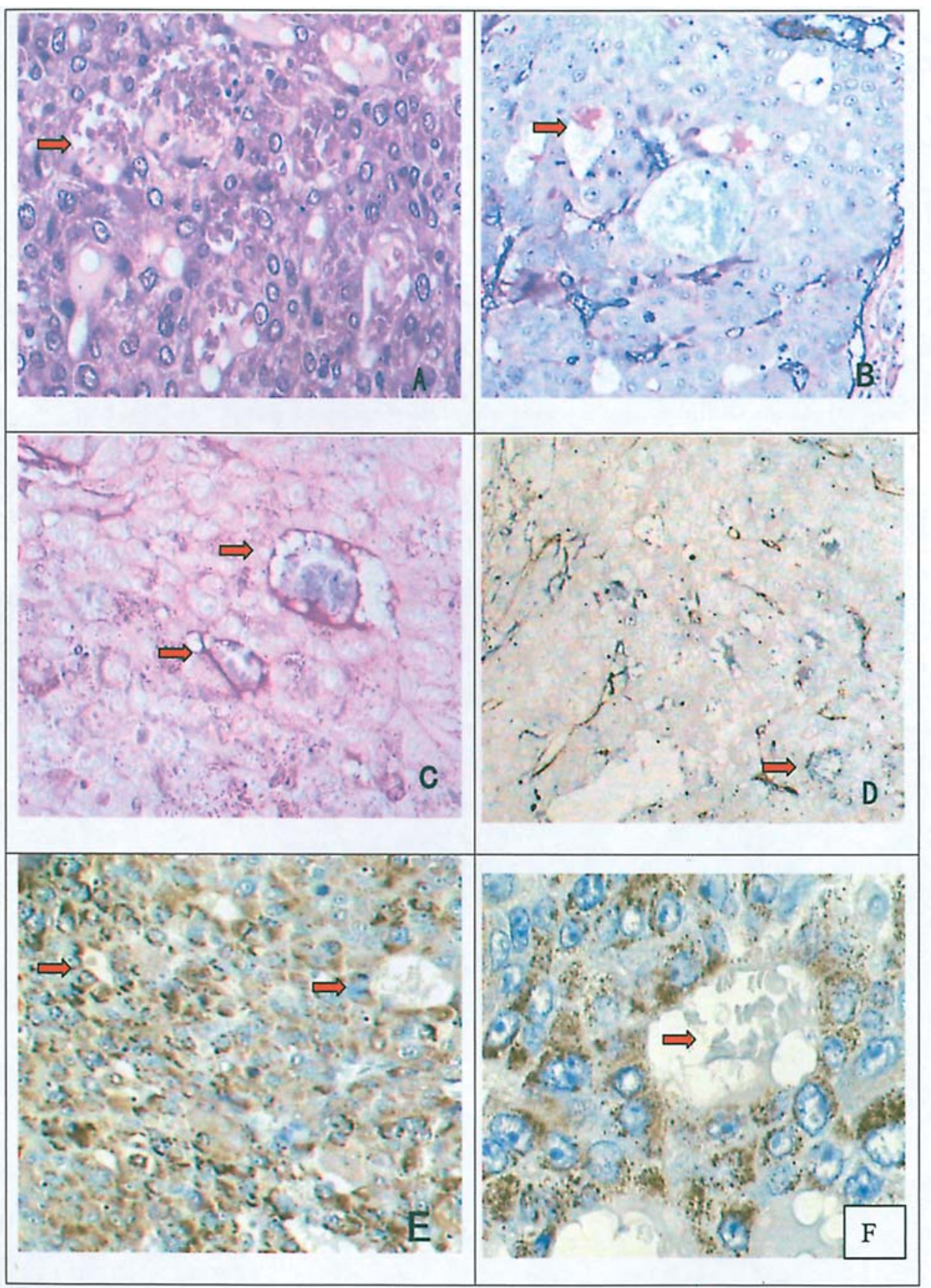

Figure 1. Evidence of VM in HCC. (A) Morphologic observation with H\&E staining. The channels (arrow) lined with tumor cells contained red blood cells and shuttle-like endothelium cells do not appear in the wall of VM. H\&E, x200. (B) Tumor cells were negative for CD31 and PAS double staining (arrow), x200. (C) The base membrane-like structure (arrows) between red blood cells and tumor cells was positive for PAS, x200. (D) The cells lining VM vessels were negative for CD105 (arrow), which verified that they were not endothelial progenitors. x100. (E) The cells lining VM were positive for hepatocyte (arrows), x100. (F) Further magnification of (E). Red blood cells appeared inside the VM vessels (arrow) x400.

Table I. Differences among VEGF, MMP-2, and MMP-9 expression between the VM and non-VM groups.

\begin{tabular}{|c|c|c|c|c|}
\hline \multirow[b]{2}{*}{ Stain } & \multicolumn{2}{|c|}{ Tissue samples } & \multirow[b]{2}{*}{$\mathrm{t} / \mathrm{Z}^{\mathrm{a}}$} & \multirow[b]{2}{*}{ P-value } \\
\hline & VM & Non-VM & & \\
\hline VEGF & $2.33 \pm 2.23$ & $3.24 \pm 2.11$ & -1.387 & 0.169 \\
\hline MMP-2 & $5.50 \pm 0.52$ & $4.07 \pm 1.539$ & 3.184 & 0.002 \\
\hline MMP-9 & $5.67 \pm 0.49$ & $4.25 \pm 1.83$ & 2.659 & 0.009 \\
\hline
\end{tabular}

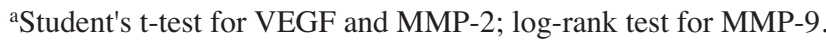

that they were HCC cells (Fig. 1E and F). In addition, VM channels were most frequently observed in the boundary regions between the tumors and surrounding normal tissues. VEGF was positive in the cytoplasms of many HCC cells as well as in the extracellular matrix. The positive rate of VEGF expression in HCC was 58\% (57 of 99 samples). The VEGFpositive rates in the VM and non-VM groups were $42 \%$ and $60 \%$, respectively. This difference was not statistically significant $(\mathrm{P}=0.169)$ (Table I).

$V M$ associated with high Edmondson tumor grade. To determine the clinical significance of VM in HCC, we 

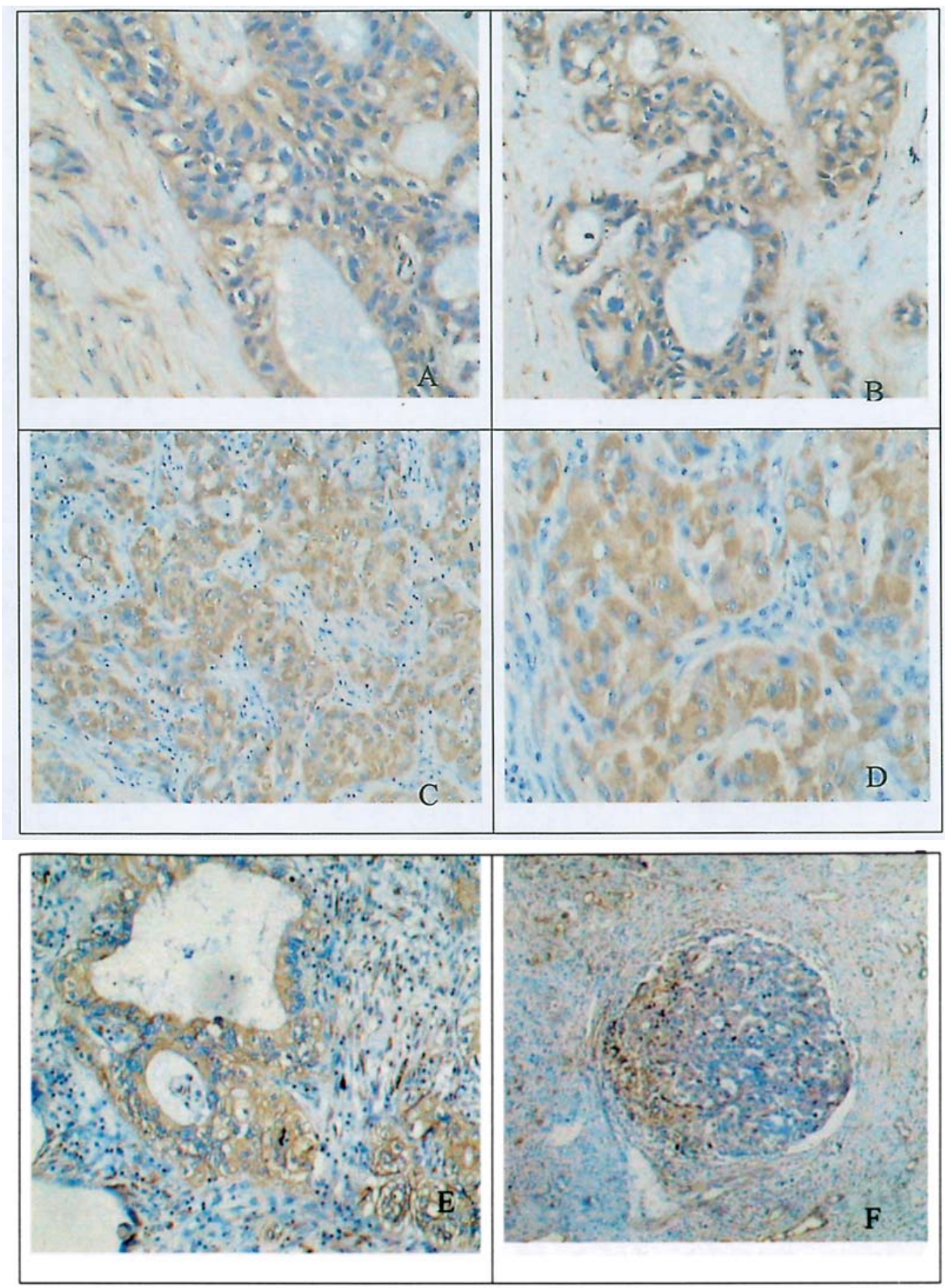

Figure 2. MMP-2 and MMP-9 expression in HCC. (A) Positive MMP-2 expression in breast cancer tissue. x400. (B) Positive MMP-9 expression in breast cancer tissue. x400. (C and D) MMP-2-positive staining in HCC cells. (C) x100, (D) x200. (E) HCC cells expressed MMP-9-positive material in the plasma. x100. (F) HCC cells had strong MMP-9 expression.

compared the presence of VM with the Edmondson grade. VM was positive in $2.5 \%$ ( 1 of 40 ) of Edmondson grades I and II tumors (low-grade) and 19\% (11 of 59) of Edmondson grades III and IV tumors (high-grade). This difference was statistically significant $\left(\mathrm{P}=0.036 ; \chi^{2}=4.416\right)$.

VM associated with metastasis. Metastatic tumors are associated with a high degree of angiogenesis. Thus, it was not surprising that the rate of metastasis in the VM group was $58 \%$ ( 7 of 12 patients) compared with $16 \%(14 / 87=16 \%$ ) in the non-VM group, according to the clinical data. This difference was statistically significant $\left(\mathrm{P}=0.003 ; \chi^{2}=8.873\right)$.

To determine whether VM is associated with increased invasion, we performed immunohistochemical staining for MMP-2 and MMP-9 and found that most samples expressed both (MMP-2, 85 of 99; and MMP-9, 84 of 99) (Fig. 2). All VM tumors expressed MMP-2 and MMP-9. The positive rates of MMP-2 and MMP-9 in the non-VM group were $84 \%$ (73 of 87 ) and $83 \%$ (72 of 87), respectively. The differences in the staining indexes of MMP-2 and MMP-9 expression in 


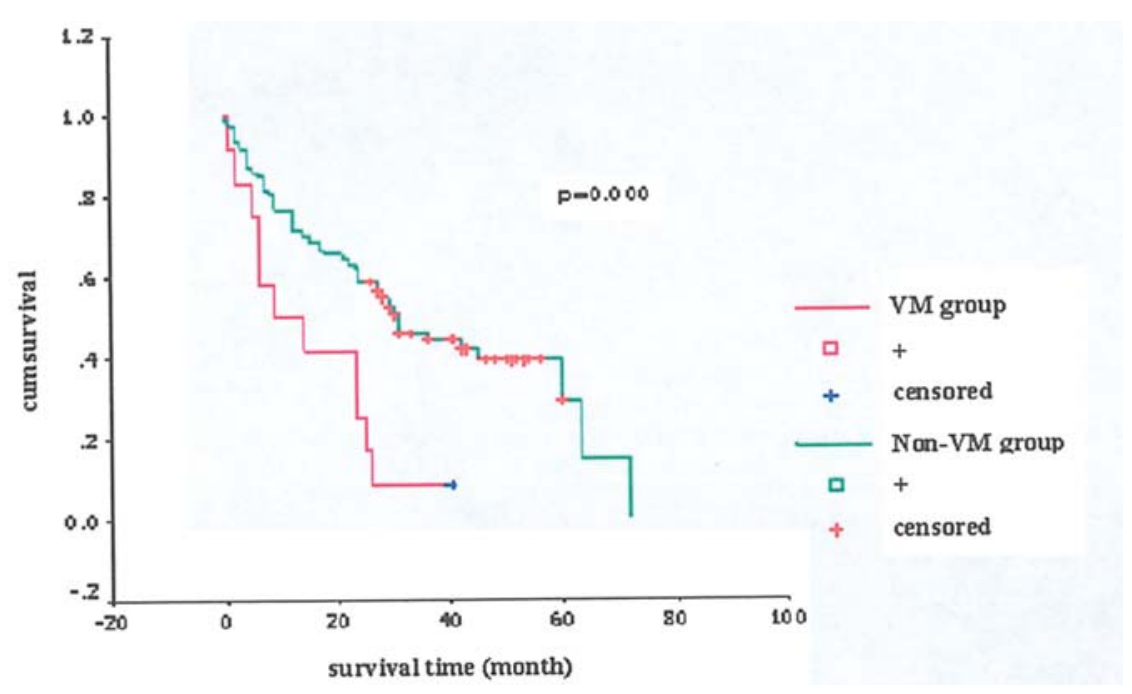

Figure 3. Kaplan-Meier survival analysis of the VM and non-VM groups in HCC.

the $\mathrm{VM}$ and non-VM groups were statistically significant $(\mathrm{P}<0.05)$ (Table I).

VM associated with short survival. We compared the survival rates between the VM and non-VM groups with a KaplanMeier survival analysis and found that VM was a predictor of poor prognosis. The patients with VM had a shorter survival than did those without VM (Fig. 3).

\section{Discussion}

To our knowledge, this is the first report on the presence of VM in HCC. VM was associated with a high HCC grade, invasion and metastasis, and short survival. Thus, VM is a marker of poor clinical prognosis in HCC.

Angiogenesis is a well-established mechanism that sustains the aggressive growth of high-grade tumors. Tumor cells can make angiogenesis factors and recruit normal endothelial cells to form blood vessels to support tumor proliferation and expansion (16-19). The existence of VM shows that tumor cells have more than one 'trick' to ensure their food supplies. Under conditions that are being extensively investigated, cancer cells have tremendous plasticity and can alter their cell type to allow them to function as other cell types (20-23). In VM, hepatocytes become endothelial-like cells and function as vessels. Whether these cells are derived from true hepatocytes or cancer stem cells present in the tumor remains to be investigated. It is conceivable that a population of stem cells exists in high-grade HCC and that this stem cell population is responsible for forming VM $(24,25)$. However, the fact that VM cells were negative for CD31 and CD105 shows that these cells do not differentiate into endothelial cells $(26,27)$. Therefore, these putative stemlike cells, if they do exist, may be committed to the hepatocyte lineage and may also be responsible for HCC formation.

VM poses a major challenge to antiangiogenesis treatment. Some antiangiogenesis drugs, such as angiostatin and endostatin, have low effectiveness in the treatment of HCC (13). One reason for this is that therapy that only targets angiogenesis may not affect VM. Steeg (28) pointed out that angiogenesis inhibitors could have the unintended effect of promoting metastasis by increasing VM.

Therefore, therapy that targets both classic angiogenesis and VM is needed. VE-cadherin is an important component of both VM and endothelium-dependent vessels (30). The specific antibody of VE-cadherin, which was used by Liao et al (31) to treat Lewis lung cancer and other epithelial tumors, may affect tumors with VM. Hess et al (32) reported that blocking the action of tyrosine protein kinase and knocking out EphA2 can prevent the formation of VM. Sood et al (8) and Seftor et al (33) proposed that antibodies to MMPs and the laminin 5 gamma 2 chain could be used to treat tumors with VM. Chemically modified tetracycline COL-3, introduced by Seftor et al (29), can restrain the expression of genes involved in invasion and metastasis and may be useful in preventing tumors from developing vessels by VM.

High-grade $\mathrm{HCC}$ has a poor prognosis. In this study, we provided evidence that VM was associated with metastasis in HCC. This is logical because HCC with VM is more likely to metastasize to other sites. Without VM, tumor cells must pass though the barrier formed by endothelial cells to enter the circulation. Tumor cells lining VM vessels, however, are exposed directly to the blood flow and can easily enter the circulation. Moreover, we identified VM as a prognostic factor for HCC. Further studies of the molecular events underlying VM will likely offer new insights into the development of complementary therapeutic strategies for antiangiogenesis in HCC and other malignant tumors with VM.

\section{Acknowledgements}

This study was partly supported by a grant from the National Nature Science Foundation of China (No. 30370554). We thank Ms. Ann Sutton for her editorial assistance.

\section{References}

1. Maniotis AJ, Folberg R, Hess A, Seftor EA, Gardner LM, Pe'er J, Trent JM, Meltzer PS and Hendrix MJ: Vascular channel formation by human melanoma cells in vivo and in vitro: vasculogenic mimicry. Am J Pathol 155: 739-752, 1999. 
2. Bissell MJ: Tumor plasticity allows vasculogenic mimicry, a novel form of angiogenic switch. A rose by any other name. Am J Pathol 155: 675-679, 1999.

3. Hess AR, Seftor EA, Seftor RE and Hendrix MJ: Phosphoinositide 3 -kinase regulates membrane type 1-matrix metalloproteinase (MMP) and MMP-2 activity during melanoma cell vasculogenic mimicry. Cancer Res 63: 4757-4762, 2003.

4. Hendrix MJ, Seftor EA, Kirschmann DA, Quaranta V and Seftor RE: Remodeling of the microenvironment by aggressive melanoma tumor cells. Ann NY Acad Sci 995: 151-161, 2003.

5. Sun B, Zhang S, Zhao X and Hao XS: Study on vasculogenic mimicry in malignant melanoma. Chung Hua Ping Li Hsueh Tsa Chih 32: 539-543, 2003.

6. Shirakawa K, Kobayashi H, Sobajima J, Hashimoto D, Shimizu A and Wakasugi $\mathrm{H}$ : Inflammatory breast cancer: vasculogenic mimicry and its hemodynamics of an inflammatory breast cancer xenograft model. Breast Cancer Res 5: 136-139, 2003.

7. Sharma N, Seftor RE, Seftor EA, Gruman LM, Heidger PM Jr, Cohen MB, et al: Prostatic tumor cell plasticity involves cooperative interactions of distinct phenotypic subpopulations: role in vasculogenic mimicry. Prostate 3: 189-201, 2002.

8. Sood AK, Fletcher MS, Coffin JE, Yang M, Seftor EA, Gruman LM, Hendrix MJ, et al: Functional role of matrix metalloproteinases in ovarian tumor cell plasticity. Am J Obstet Gynecol 190: 899-909, 2004.

9. Hao X, Sun B, Zhang S and Zhao X: Microarray study of vasculogenic mimicry in bi-directional differentiation malignant tumor. Chung Hua I Hsueh Tsa Chih 82: 1298-1302, 2002.

10. Yue WY and Chen ZP: Does vasculogenic mimicry exist in astrocytoma? J Histochem Cytochem 53: 997-1002, 2005.

11. Hoffmeyer MR, Wall KM and Dharmawardhane SF: In vitro analysis of the invasive phenotype of SUM 149, an inflammatory breast cancer cell line. Cancer Cell Int 5: 11-20, 2005.

12. Bosch FX, Ribes J, Cleries R and Diaz M: Epidemiology of hepatocellular carcinoma. Clin Liver Dis 9: 191-211, 2005.

13. Srivatanakul P, Sriplung $H$ and Deerasamee $S$ : Epidemiology of liver cancer: an overview. Asian Pac J Cancer Prev 5: 118-125, 2004.

14. Dupuy E, Hainaud P, Villemain A, Bodevin-Phedre E, Brouland JP, Briand P, et al: Tumoral angiogenesis and tissue factor expression during hepatocellular carcinoma progression in a transgenic mouse model. J Hepatol 38: 793-802, 2003.

15. Mattern J, Koomagi R and Volm M: Association of vascular endothelial growth factor expression with intratumoral microvessel density and tumour cell proliferation in human epidermoid lung carcinoma. Br J Cancer 73: 931-934, 1996.

16. Sun B, Zhang S, Zhao X, Zhang W and Hao X: Vasculogenic mimicry is associated with poor survival in patients with mesothelial sarcomas and alveolar rhabdomyosarcomas. Int $\mathbf{J}$ Oncol 25: 1609-1614, 2004.

17. Forsythe JA and Jiang BH: Activation of vascular endothelial growth factor gene transcription by hypoxia-inducible factor. Mol Cell Biol 16: 4604-4613, 1996.

18. Gleadle JM, Ebert BL, Firth JD and Ratcliffe PJ: Regulation of angiogenic growth factor expression by hypoxia transition metals and chelating agents. Am J Physiol 268: 1362-1368, 1995.
19. Stepien O, Zhang Y, Zhu D and Marche P: Dual mechanism of vascular endothelial growth factor upregulation by hypoxia in human hepatocellular carcinoma. Gut 48: 87-96, 2001.

20. Hendrix MJ, Seftor EA, Kirschmann DA and Seftor RE: Molecular biology of breast cancer metastasis molecular expression of vascular markers by aggressive breast cancer cells. Breast Cancer Res 2: 417-422, 2000.

21. Hendrix MJ, Seftor EA, Hess AR and Seftor RE: Vasculogenic mimicry and tumour-cell plasticity: lessons from melanoma. Nat Rev Cancer 3: 411-421, 2003.

22. Hao X, Sun B and Zhang S: Correlation between the collagen IV, VEGF and vasculogenic mimicry. Chung Hua Chung Liu Tsa Chih 25: 524-526, 2003.

23. Van der Schaft DW, Seftor RE, Seftor EA, Hess AR, Gruman LM, Kirschmann DA, et al: Effects of angiogenesis inhibitors on vascular network formation by human endothelial and melanoma cells. J Natl Cancer Inst 96: 1473-1477, 2004.

24. Sood AK, Fletcher MS and Hendrix MJ: The embryonic-like properties of aggressive human tumor cells. J Soc Gynecol Investig 9: 2-9, 2002.

25. Sell S: Cellular origin of hepatocellular carcinomas. Semin Cell Dev Biol 13: 419-424, 2002.

26. Suzuki K, Hayashi N, Miyamoto Y, Yamamoto M, Ohkawa K, Ito $\mathrm{Y}$, et al: Expression of vascular permeability factor/vascular endothelial growth factor in human hepatocellular carcinoma. Cancer Res 56: 3004-3009, 1996.

27. Kumar S, Ghellal A, Li C, Byrne G, Haboubi N, Wang JM, et al: Breast carcinoma: vascular density determined using CD105 antibody correlates with tumor prognosis. Cancer Res 59: 856-861, 1999.

28. Steeg PS: Angiogenesis inhibitors: motivators of metastasis? Nat Med 9: 822-823, 2003.

29. Seftor RE, Seftor EA, Kirschmann DA and Hendrix MJ: Targeting the tumor microenvironment with chemically modified tetracyclines: inhibition of laminin 5 gamma 2 chain promigratory fragments and vasculogenic mimicry. Mol Cancer Ther 1: 1173-1179, 2002.

30. Seftor EA, Meltzer PS, Kirschmann DA, Pe'er J, Maniotis AJ, Trent JM, et al: Molecular determinants of human uveal melanoma invasion and metastasis. Clin Exp Metastasis 19: 233-246, 2002.

31. Liao F, Li Y, O'Connor W, Zanetta L, Bassi R, Santiago A, et al: Monoclonal antibody to vascular endothelial-cadherin is a potent inhibitor of angiogenesis, tumor growth, and metastasis. Cancer Res 60: 6805-6810, 2000.

32. Hess AR, Seftor EA, Gardner LM, Carles-Kinch K, Schneider GB, Seftor RE, et al: Molecular regulation of tumor cell vasculogenic mimicry by tyrosine phosphorylation: role of epithelial cell kinase (Eck/EphA2). Cancer Res 61: 3250-3255, 2001.

33. Seftor EA, Meltzer PS, Schatteman GC, Gruman LM, Hess AR, Kirschmann DA, et al: Expression of multiple molecular phenotypes by aggressive melanoma tumor cells: role in vasculogenic mimicry. Crit Rev Oncol Hematol 44: 17-27, 2002. 